\title{
ELLIPSIS OF SHARED SUBJECTS AND DIRECT OBJECTS FROM SUBSEQUENT PREDICATIONS IN EARLIER EGYPTIAN*
}

\author{
By CARSTEN PEUST
}

In this paper I discuss subject and object ellipsis from the second of two linked predications, where predication is meant as a cover term for both finite clauses and infinite verbal formations. Two different types of ellipsis are described. The first type is realized by using either $h r+$ infinitive or a stative, these constructions occurring in complementary distribution. I show that this kind of ellipsis is equally possible for subjects and objects. This feature distinguishes Egyptian from European languages, where subjects are preferred targets for ellipsis. The possibility for the subject and the object to be elided together is particularly noteworthy and has not been adequately recognized to date. A second type of ellipsis is characterized by omission of the pronominal subject in verb forms of the $s \underline{d}=f$ conjugation. This construction is more restricted in use and is found only in a chain of clauses that are largely parallel in structure.

WHEN two linked clauses share common elements, it is usual in many languages for identical elements in the second clause to be omitted. In the case of subsequent coordinated main clauses, this phenomenon is typically described as coordinate ellipsis or coordination reduction in the linguistic literature. An important rule for English is that coordinate ellipsis affects subjects more readily than objects. In the clause sequence 'I saw a book yesterday and I bought it', the subject and object of both clauses are identical in reference. It is possible to delete the subject ' $I$ ' in the second instance, but not the object 'it', the result being 'I saw a book yesterday and ø bought it'. The ellipsis position is symbolized by 'ø' here and throughout this paper. ${ }^{1}$

In order to recover the correct interpretation of a zero subject, the essential strategy in English is to assume that it is coreferential with the explicit subject of the conjoined clause. For example, in the utterance 'the stick hit the pot and broke', the subject of 'broke' is missing and has obviously undergone coordination reduction. The utterance can nevertheless be interpreted without ambiguity: it must be the stick that broke and not the pot. This is because the zero subject of the second clause is assumed to be coreferential with the subject, and not the object, or some other element, of the conjoined clause.

The behaviour of the other European languages is more or less similar to English

\footnotetext{
* I have profited greatly from discussions with Anne Morrison (Adelaide) and Wolfgang Schenkel (Tübingen), who read a draft of this paper. I am also very thankful to the Editor as well as the anonymous referees whose insightful and detailed comments contributed to a substantial reshaping and clarification of this article.

Terms such as 'ellipsis', 'deletion', and the symbol ' $\varnothing$ ' are used here for convenience to indicate missing elements which are nevertherless functionally reconstructible. I do not necessarily share the classical generative view that all the structures with 'elision' are secondary in a derivational sense and that the empty positions are actually filled in 'deep structure' representations of the clauses in question.
} 
in this respect. There are, however, languages in other parts of the world in which the object of a transitive verb takes a more nuclear position in the clause and is in this respect equivalent to the subject of an intransitive clause. Here, interclausal noun phrase coherence works by object identity rather than subject identity (for transitive clauses), a behaviour that is called 'syntactic ergativity'. One language known as being strongly syntactically ergative is Dyirbal (Australia), from which the following example is taken:

\section{yadya iinuna balgan, baninyu}

(lit.: I - you - hit - came)

I hit you, and you (not: I) came here. ${ }^{2}$

We see here that the deleted zero subject of the (intransitive) second conjoined clause must be interpreted as coreferential with the object, and not the subject, of the (transitive) first clause. This is quite different from the pseudo-literal English translation 'I hit you and came'.

In English and other languages, omission rules can be quite different when, instead of coordinated main clauses, combinations of a main clause and a subordinate clause or a non-finite secondary predication are involved. For example, the subject of an infinitive phrase can be deleted under coreference with a preceding subject ('I want $\varnothing$ to go'), which parallels the behaviour of coordinated main clauses, but also under coreference with other parts of the sentence ('I asked him ø to go'; the structural subject *'he' of the infinitive is deleted due to coreferentiality with the preceding direct object).

The goal of the following discussion is to clarify the rules of actant ellipsis in Egyptian. I restrict my attention to the earlier period of the language and consider ellipsis of subjects and direct objects only, to the exclusion of other elements of the sentence. As is well known, a distinction between main and subordinate clauses in Egyptian is generally hard to draw in a running text, and the syntactical interpretation of the central verbal formations of the language is still far from clear. Doubts can also be raised about the relevance of the finite versus infinite distinction. For example, the combination of $h r+$ infinitive on the one hand, which is prototypically infinite, and the stative verb on the other, which would be analysed as finite, occur in largely the same syntactic environments and thus turn out to be syntactically equivalent.

It has therefore been decided here not to put any emphasis on the distinction between gapping in coordinated and in subordinated structures, nor on the distinction between finite and infinite chained predications. For the time being, it is assumed, rather, that the gapping behaviour of two subsequent $s \underline{d} m=f$ verbal forms is the same regardless of whether the second predicate is a 'circumstantial' or a 'verbal' verb form, neither will I attempt to distinguish between a $h r s \underline{d} m$ construction that calls for a translation as a coordinated main clause ('and I/you/he heard') and the same construction in a context where it would more readily be translatable as a subordinate structure into English ('while I/you/he heard').

2 From B. Comrie, Language Universals and Linguistic Typology: Syntax and Morphology (2nd edn; Oxford, I 989), I I3. Note that Dyirbal does not encode grammatical person on verbs, so that the verb baninyu, taken out of context, would not have any specific 2 nd person reference. 


\section{Eliding a transitive subject before $\underline{h r}+$ infinitive}

A common ellipsis strategy of Earlier Egyptian involves the use of the preposition $h r$ followed by an infinitive. The result is a non-initial predication lacking an overt subject. I am going to discuss cases first in which the verb of the second clause is transitive:

(I) Urk. I, 86.I6-I7 (restoration based on Urk. I, 86. I 5):

jri.n=(j) rw.t jm ø hr hrp $[k 3 . t]$

I ran the office there and (or: while I) led the work.

This construction can be viewed as an abbreviation of a clause sequence *jri.n=j rw.t $j m$, $j w=j h r h r p k 3 . t$ 'I ran the office there, and (or: while) I led the work' in which the subject pronoun $=j$ (supported by its carrier element $j w$ ) is repeated. Here, and in general, the unelided structures would probably have been acceptable as well, just as they are in English. Chained clauses with shared elements but no ellipsis are extremely frequent in Egyptian. ${ }^{3}$

Ellipsis before $h r+$ infinitive is not dependent on the condition that the element to be elided acts as a subject in the first clause. In fact, if the subject of the second clause is elided, its antecedent in the first clause may equally function as a transitive subject, an intransitive subject, a passive subject, or an object (or possibly have other functions, an issue not considered here). Examples for all four combinations follow:

Transitive subject in the first clause = transitive subject in the second clause

(2) Urk. IV, 345.I-2:

š̌m.n=(j) st ḥr mw ḥr tз ø hrrwb3 n=sn w3.wt št3.wt

After I led them on water and land and (after I) opened hidden ways for them.

(3) P. Heqanakht II, 5 = J. P. Allen, The Heqanakht Papyri (PMMA 27; New York, 2002), pl. $\mathrm{xxx}$ :

$m=\underline{t} n$ ph $. n=j$ p 3 hrw jm=tn $n$ ø $h r$ senh $=\underline{t} n$

I reached this day with you while (I) nourished you.

Intransitive subject in the first clause = transitive subject in the second clause

(4) Urk. IV, 370.I6-I 7:

jwi $n=s$ wr.w n.w ḩs .wt ø hr dbh htpw

The chiefs of foreign countries come to her and request peace (or: requesting peace).

(5)Urk. I, 222.2:

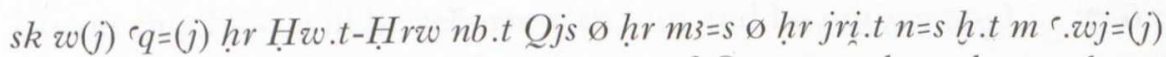

While I entered to Hathor, the mistress of Qusae, and saw her and performed the ritual for her with my (own) hands.

3 Two examples will suffice: $r \underline{d i} i c=f h r z, j w=f r h s w$ '(about a physician:) who lays his hand on somebody and diagnoses him', R. Anthes, Die Felseninschriften von Hatnub (UGAÄ 9; Leipzig, I 928), 34 graffito I 5,5; gmi.n sw wpwtj.w hr ws.t, ph.n=sn sw $r$ tr $n$ ḩswj 'the messengers met him on the road, and they reached him at night-time', Sinuhe R 19-20 = R. Koch, Die Erzählung des Sinuhe (BAe 17; Brussels, 1990), 10. 
Passive subject in the first clause = transitive subject in the second clause

(6) I. Gamer-Wallert, 'Das Grab des Hohenpriesters des Ptah, Mrj-Pth, in Saqqara', WdO I4 (1983), I I 9 fig. 9, col. 3 :

jr wnn 3 h.tw ø hr jri.t m3r.t

If one becomes a spirit by doing truth.

(7) P. A. A. Boeser, Beschreibung der aegyptischen Sammlung der Niederländischen Reichsmueums der Altertümer in Leiden, VI: Die Denkmäler des Neuen Reiches, III: Stelen ('The Hague, I913), pl. i, 1. 7-8:

pri.n.t(w) $r$ rwtjø $h r \underline{d} d r=j: \varsigma_{3} . w(j)$ sj $h z w . t=f$

(Even) when people went abroad, (they) said of me: he is favoured so much!

Object in the first clause $=$ transitive subject in the second clause

(8) Sinuhe R $142=$ R. Koch, Sinuhe, 47 :

$h r m 33=f w j \varnothing h r$ jri.t $w p[w . t]=k$

Because he sees me while (I) do your mission.

(9) R. A. Caminos, Literary Fragments in the Hieratic Script (Oxford, I956), pl. iiA, 11. 4-5:

$m 33=j m s . w$ Hw.t-jhy.t $\varnothing ~ h r q m[3]$ wj3.t

I watch the children of Hw.t-jhy.t while (they) hunt wjjs.t-birds.

\section{Eliding an intransitive subject before $h r+$ infinitive or a stative}

The subject of an intransitive verb can also be elided from the second clause. In this case, reduction is possible not only by using $h r+$ infinitive, but by using a stative verb as well. First, some examples for the reduction to $h r+$ infinitive:

Transitive subject in the first clause $=$ intransitive subject in the second clause

(г) CT II, 94b:

$\underline{d} \underline{i}=f s \underline{h r} m 3 s . t=f ø \underline{h r} p \rho g$

(A man shall utter this spell over a louse of his head), he shall put it on his knee and spit.

(I I) Urk. IV, I I 08. I 5:

jr gr.t jri.t. $n b \underline{t} \underline{t} t j ø h \underline{h r} s \underline{d} m m \underline{h 3}=[f]$

As for everything the vizier does when (he) holds an interrogation in his office.

Intransitive subject in the first clause $=$ intransitive subject in the second clause

(12) Urk. I, I 29.6-7:

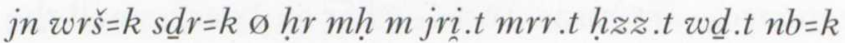

Truly, you spend day and night pondering about doing what your lord loves, praises, and commands.

(13) G. Posener, 'Le conte de Néferkarê et du général Siséné', $R d E$ I I (I 957), I 26, 1. x+ I 4: pri.nspr.wn Mn-nfrø hr rmi.t r 3 wr.t

The petitioner from Memphis went out and cried (or: crying) a lot. 
Passive subject in the first clause = intransitive subject in the second clause

( 4 4) P. Vernus, 'La stèle du Pharaon Mntw-htpi à Karnak', RdE 40 (I989), I47, 1. 3:

hre.tw ø hr nhm r-ḩ.t=f

(A king) before whom one rejoices and jubilates. ${ }^{4}$

Object in the first clause = intransitive subject in the second clause

(15) W. Helck, Die Prophezeiung des Nfr.tj (2nd rev. edn; Wiesbaden, I992), I8: $n h m=s n$ htr.w ø hr sk3

They rob the teams of horses while (the teams) are doing fieldwork.

(r6) Peasant BI, 65-6 = R. Parkinson, The Tale of the Eloquent Peasant (Oxford, I 991), I4: gmi.n=f sw ø hr pri.t $m s b 3 n$ pr=f

He found him going out of the door of his house.

The following are examples of reduction with a stative verb: ${ }^{5}$

Transitive subject in the first clause = intransitive subject in the second clause

(17) Sh.S. 4I = A. M. Blackman, Middle-Egyptian Stories, I (BAe 2; Brussels, I 932), 42: jri.n=j hrw 3 ø wr.kw

I spent three days being alone.

(I8) Urk. IV, 429.4-5:

$r \underline{d i} . n=f w(j) r s s ̌ m ~ c h ø r h . w n t<t>(\ldots)$

He installed me as manager of the palace (because he) knew that (...).

Intransitive subject in the first clause $=$ intransitive subject in the second clause

(i9) $P T$ i34a:

$n \stackrel{s}{m} . n=k j s$ ø $m w t . t j, \breve{s} m . n=k \emptyset\ulcorner n h .[t]$

You have not gone being dead, you have gone being alive.

(20) CT V, 321g:

jwi.n $n=k N N$ tn $\varnothing$ nhh.tj

This NN has come to you while (she) is old.

Passive subject in the first clause = intransitive subject in the second clause

(2I) $C T$ III, 276c:

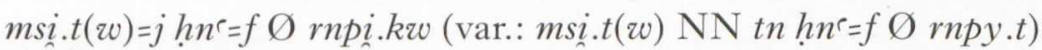

I (var.: this NN) will be reborn with him and be rejuvenated.

4 Second Intermediate Period text. her.tw appears to be the passive of the relative form which comes into use in post-classical Middle Egyptian; cf. A. H. Gardiner, Egyptian Grammar (3rd edn; Oxford, I 957), §388.

5 I consider the subject as being elided here as well, although the stative verb has personal endings that agree with the subject, e.g. $-k w=$ Ist sg. in the next example. In spite of its person marking, the syntactical behaviour of the stative is largely parallel to that of $h r+$ infinitive. Both may or may not be preceded by an explicit subject pronoun under largely the same conditions. The major point of difference lies in the fact that the Ist sg. of the stative, the form whose person marking is the least ambiguous within the paradigm, can also be used as an independent verbal predicate (Gardiner, Egyptian Grammar, §312); this possibility is not available for hr + infinitive. 
(22) CT II, I66e:

$j w=j m s i . k \varnothing$ wsr. $k r=f$ (var.: $j w$ NN $m s i$ ø $w s r . j r=f$ )

I was born (var.: he was born) being mightier than him.

Object in the first clause $=$ intransitive subject in the second clause

(23) CT I, 20Ic:

$m 33=s n$ tw $\varnothing j y . t \varnothing$ hri.t (var.: $m_{33}=s<n>\mathrm{NN} p n$ jwi hri. $w$ )

When they see you (var.: this $\mathrm{NN}$ ) coming and appearing.

(24) Urk. IV, I 281.4-5:

sti.t ch $_{3} r$ stw $m$ bjs $\varnothing$ pri.w jm=f $\varnothing$ di..$w r t 3$

To shoot an arrow to a butt of copper so that (the arrow) comes out of it and is brought to the ground.

The choice between $h r+$ infinitive and stative reflects an aspectual opposition between process ( $h r+$ infinitive) and state (stative), see Gardiner, Egyptian Grammar ${ }^{3}$, \$20. In addition to Gardiner's statements, it should be noted that the stative is the default choice for verbs of movement, whereas $h r+$ infinitive here has an ingressive reading, cf. R. Hannig, Pseudopartizip und $s \underline{d} m . n=f$ : Der Kernbereich des mittelägyptischen Verbalsystems, II (HÄB 32; Hildesheim, I99 I), I I I and I 27-30.

It is interesting to observe that intransitive clauses, being typologically intermediate between transitive-active and transitive-passive clauses (treated in the next section), combine the syntactic possibilities of both clause types.

\section{Eliding a passive subject (semantic patient) before a stative}

It is also possible to elide the semantic patient from the second clause, i.e. the element which, if overt, would have to be expressed either as a direct object or as the subject of a passivized verb. Here, the verb takes the form of a stative, i.e. it is passivized. These cases are structurally identical to those in which an intransitive subject is elided before a stative. This distinction can be difficult or impossible to make for verbs that can be either transitive and intransitive. Some examples:

(25) L. Habachi, The Second Stela of Kamose and his Struggle against the Hyksos Ruler and his Capital (ADAIK 8; Glückstadt, I 972), 4I:

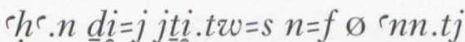

Then I let it (= the message) be brought to him, so that (it) returned (taking enn as intransitive) $\sim$ so that (it) was returned (taking ' $n n$ as transitive)'. (More freely: 'I let it be brought back to him'.)

(26) CT VI, 327m:

$h 3 i=k m-m$ sh.w ø $\mathrm{p}$ r.tj $m n \underline{t} r \underline{d} s=f$

You will go down among the spirits and be provided like a very god.

(27) Urk. IV, II2.I7-II3.I:

$z m s=k$ h.t $m-m$ jry ø s $h . t j m \underline{d} p j . w$ ḩzy.w

May you receive offerings among them and be honoured among the best of the praised ones. 
(28) Urk. IV, I 20.6:

hzy pri $m$ h.t. ø hzi.w

A praised one who came out of the womb (already) being praised.

In all the cases given, the agent has been left unexpressed in the second conjunct. It could, a priori, be expected that an explicit agent could be appended by means of the preposition $j n$, a possibility attested for a passive stative verb in other contexts (Gardiner, Egyptian Grammar, $\$ 39$ end). This would make sense as an ellipsis strategy for two clauses which have a common object but different predicates and subjects. I have not, however, encountered any such examples. The normal way of combining two clauses with only the object in common is to avoid ellipsis altogether, e.g.:

(29) CT II, 35 rc-352a:

$h 3 m=f$ st, srd st $m w . t=f 3 s . t r$ s.t jrj.t

He shall fish them out (= the hands of Horus), and his mother Isis shall implant them at their proper place.

The unattested corresponding construction with ellipsis would be *h3m=f st $\varnothing$ srd. $(w)$ jn mw.t $=f$ ss.t.

\section{Double ellipsis of subject and object}

An interesting situation arises when two subsequent predications share both their subjects and their objects. As described above, it is common in English to elide the shared subject, but not the shared object: 'I saw a book yesterday and ø bought it'. In Egyptian, a superficially similar construction can occur when the initial clause has a pseudoverbal predicate so that both clauses become parallel in structure:

Urk. I, 127.7-9:

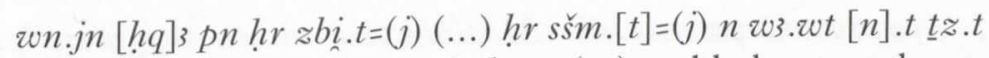

Then this ruler accompanied me (...) and led me on the mountain paths.

However, it is doubtful whether this is a genuine case of ellipsis from a subsequent clause, i.e. a structure that could be symbolized as [wn.jn hqq3 pn hrr zbi.t=j ...] [ø hrr $s \check{s} m . t=j \ldots]$. A more plausible analysis is to assume a coordination only of the predicate element, i.e. of a constituent within a single clause: wn.jn hqu $p n$ [hr zbi.t=j ...] $[h r$ sšm $. t=j \ldots]$.

Focussing on examples where the first clause is verb-initial, as is more typical for Earlier Egyptian, instances of subject ellipsis with no simultaneous object ellipsis turn out to be extremely uncommon. I can cite only one example from the later Eighteenth Dynasty:

(3i) H. M. Stewart, 'Some Pre-‘Amārnah Sun-Hymns', $7 E A 46$ ( r 960), 86 middle:

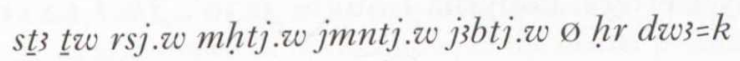

The southerners, northerners, westerners, and easterners tow you and adore you.

Ordinarily, both the subject and the object are elided from the second clause, with the verb taking stative morphology just as it does in the case of object ellipsis discussed above: 
(32) Urk. IV, I684.10-II:

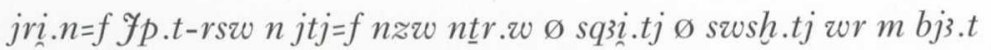

He built Luxor for his father, king of the gods, and made (it) very high and wide like a wonder.

An English-style structure such as *jri.n=f $\not p$ p.t-rsw (...) ø hr sq3i.t=s (...) with subject ellipsis and preserved object would be abnormal and probably ungrammatical for classical Egyptian.

This structure involving a stative verb is ambiguous as to whether the agent is identical to that in the first clause ('... and he made it high') or vague ('... and it was made high'). However, in the example given here, it is noteworthy that the stative of the causative was chosen rather than of the simple verb (*q3i.tj 'and it was high'). This is probably meant to indicate that some agent is implied in the action. The implied agent can, in this context, only be the subject of the previous clause.

Below, I provide further illustration of the double ellipsis construction which has hitherto gone unnoticed in the grammars despite its high textual frequency (examples with unambiguous stative morphology are preferred):

(33) Typical MK phraseology, e.g. CG 20 I 53, $4=$ H. Lange \& H. Schäfer, Grab- und Denksteine des Mittleren Reichs im Museum von Kairo (CGC Nos 2000 I-20780; Berlin, 1902), I, I 80 :

jri.n=j $n=j$ mehr.t tw ø ssh.tj

I built this tomb for myself and perfected (it).

(34) P. Moscow 314, I 2,2 = A. Erman, Hymnen an das Diadem der Pharaonen (Berlin, I 9 I ), 42:

$m j n=k \operatorname{snj} \varnothing \operatorname{smn}\{n\} . t j m \underline{d} p=k$

Take them (= the crowns) to you and fix (them) on your head.

(35) P. Ebers 37, I5 = H. Grapow, Grundriss der Medizin der altern Ägypter, V: Die medizinischen Texte in hieroglyphischer Umschreibung autographiert (Berlin, I 958), I 54: $r \underline{d i} . h r=k \underline{d} r . t=k h r=f \varnothing q 3 h . t j$

Then you are to put your hand upon him (= the patient) and bend (it).

(36) P. Ebers 107,4-5 = Grapow, Grundriss der Medizin V, 391:

jri.hr $h=k n=s \underline{d} w$-r ø srwh.tj $m j$ srwh wbnw

Then you are to perform surgery on it (= the swelling) and treat (it) like a wound is treated.

(37) Anthes, Felseninschriften von Hatnub, 52 graffito 23,5:

$j w s$ s nh. $n=j s(j) \varnothing s(n) m . t r-\underline{d} r=s$

I let it (= my town) live and nourished (it) completely.

(38) T. E. Peet, 'Two Eighteenth Dynasty Letters. Papyrus Louvre 3230', FEA I2 (I 926 ), pl. xvii 2,2:

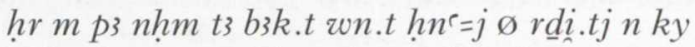

Why is that, taking the maid who was with me and giving (her) to someone else? 
(39) Urk. IV, 765.I4-1 5 (The temple built of bricks and wood had fallen into ruins):

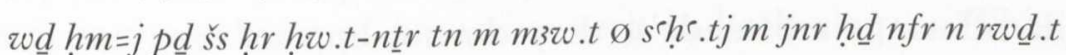

My Majesty commanded to perform the foundation ceremony for this temple anew and to erect (it) with bright high quality sandstone.

(40) E. Frood, 'Ritual Function and Priestly Narrative: The Stelae of the High Priest of Osiris, Nebwawy', $\mathscr{F} E A 89$ (2003), 60 fig. I, 1. I6:

$j w h z i . n w(j) h m n n b=j \varnothing \underline{d i} . k w r r$ - hrj

The Majesty of my lord favoured me and installed (me) as Chief Speaker.

(4I) J. Couyat \& P. Montet, Les inscriptions hiéroglyphiques et hiératiques du Ouâdi Hammâmât (MIFAO 34; Cairo, I912), no. I 13, 1. 10:

stp. $n=f w(j) h n t n^{\prime} . t=f \varnothing s s b q . k w$ hnt šnw. $t=f$

He elected me in front of his town and honoured (me) in front of his entourage.

In the constructions surveyed so far, neither the subject nor the object are particularly favoured as ellipsis targets in Egyptian, but both can be elided with equal ease. On this basis at least, no decision for or against the syntactic ergativity of the Egyptian language can be made: Egyptian is neutral with regard to the issue of syntactic ergativity.

\section{Eliding the subject of a $s \underline{d} m=f$}

We have discussed subjectless constructions of the form $h r r+$ infinitive or stative, which can be considered elliptic abbreviations of $j w+$ suffix pronoun $+h \underline{r}+$ infinitive or $j w+$ suffix pronoun + stative respectively. There are, in addition, instances of ellipsis which can be analyzed as the result of eliding the suffix pronoun from a $s \underline{d} m=f$ verbal form. Although Gardiner, Egyptian Grammar, $\$ 487$ acknowledged this possibility for a few cases, alternative explanations have often been sought for the examples in question. Consider the following sentence:

(42) N. Kanawati and A. Hassan, The Teti Cemetery at Saqqara, I (ACE Reports 8; Sydney, I 996), pl. xvii, col. 4:

$\underline{d} d . k_{3}=\underline{t} n m \quad r=\underline{t} n, w d n=\varnothing m e \underline{\underline{t} n}$

Then you shall say with your mouth and offer with your hand: (offering list follows).

I suggest that both the pronominal suffix and the tense marker have been deleted from the $s \underline{d} m . k_{3}=f$ verb of the second clause, leaving the mere stem $w d n{ }^{6}$ Although other analyses would be technically possible, such as the analysis as an imperative

\footnotetext{
${ }^{6}$ It is important to distinguish between ellipsis of one of two identical elements in succession, as described here, and another quite different usage of zero subjects which is motivated by lack of specifity of the reference noun (mass nouns, general situations, etc.), such as in $j w=\emptyset \check{s}_{3} \xi$ smn.t st $m \approx \check{s}$ 'it (= all the unspecified items hinted at previously) is too much to be recorded in writing', Urk. IV, I2II.I5. A zero pronoun of this latter type corresponds, as also shown in the example, to the neuter pronoun st in other syntactic positions. On unspecific zero pronouns, see M. Collier, 'Grounding, Cognition and Metaphor in the Grammar of Middle Egyptian', LingAeg 4 (1 994), 64-72; C. Peust, 'Objektspronomina im Ägyptischen', LingAeg 10 (2002), 3 I4-1 5; W. Schenkel, Tübinger Einführung in die klassisch-ägyptische Sprache und Schrift (Tübingen, 2005), I 54 and I68; P. Vernus, 'Études de

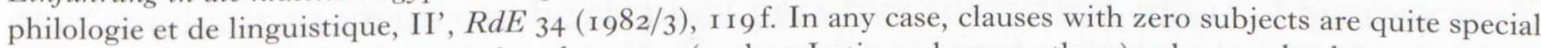
in Egyptian. Egyptian is not a pro-drop language (such as Latin and many others), where verbs do not regularly require an overt subject.
} 
('then you shall say ... offer!'), ${ }^{7}$ or as a defectively written passive $s \underline{d} m .(w)=f$ ('then you shall say ... while offerings are made'), they do not appear very convincing. ${ }^{8}$ Given the fact that coordinate ellipsis is widespread in the world's languages, I see little reason to reinterpret or emend such examples. Some more examples of what I consider ellipsis of the subject in a $s \underline{d} m=f$ form are given below:

(43) Urk. IV, 1064.14-I 5:

$m з n=k p r=k n$ enh.w, sd $m=\varnothing h r w h s j \check{s} m^{e}$

May you see your house of the living and hear the sound of singing and music.

(44) P. Chester Beatty V vs. 6,5 = Grapow, Grundriss der Medizin V, 63:

$\check{s} p=k, p r i=\varnothing m m 3^{\ulcorner} j 3 b[j]$

May you run out and come out from the right temple.

(45) Urk. IV, I I3.IO-I I:

$z m 3=k$ ts $m$ hr.t jmnt.t, hpr=ø $m$ b3 'nhy

You will be buried (lit.: join the earth) in the tomb of the West and become a living ba.

I suggest that the following examples can be understood in the same way. Elsewhere, they have been taken as evidence for $s j$ as an alternative for the 3 rd $\mathrm{sg}$. fem. stative suffix - tj (Gardiner, Egyptian Grammar, §374 end):

(46) Urk. IV, 273.9-10:

$s w \underline{d}=k$ ts pn $m[h f] e=s, \operatorname{sh} t p=\varnothing$ sj $m n z w y . t[\ulcorner] 3 . t$

May you appoint this country to her (=Hatshepsut's) grip and satisfy her with a long kingship.

(47) Urk. IV, 882.1 I-I2:

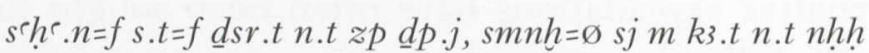

He established his holy place of the primeval time and perfected it with a work of eternity.

(48) P. Ebers 93, I6-I 7 = Grapow, Grundriss der Medizin V, 492-3:

$r \underline{d i} . h r=k$ jni.tw $n=k$ mh.t $m 3 . t, m h=\varnothing$ sj $m$ mrh.t, $r \underline{d i}=\varnothing$ hmsi $z . t h r=s r$ hrw 4

Then you shall let a new bowl be brought to you, (you shall) fill it with oil and (you shall) let the woman sit upon it for 4 days.

(49) Cairo Wb. no. $62=<$ http://aaew.bbaw.de/tla>, DZA 24108070; Ramesside era:

$r h$ jty mnh.t=f, $\underline{d i}=\varnothing$ sw $r$ m-r mnfy. $(t)$

The sovereign recognized his competence and installed him as overseer of the troops.

7 This is what E. Edel, Altägyptische Grammatik (AnOr 34 and 39; Rome, 1955 and 1964), §553 suggests for this example.

${ }^{8}$ Continuing an optative finite verb as an imperative is not a known strategy of Egyptian. The reverse order is, however, well attested: imperative + subjunctive in Earlier Egyptian; imperative + conjunctive in Later Egyptian, similar constructions being typical for other African languages. See C. Peust, 'Das Ägyptische als afrikanische Sprache', in T. Schneider (ed.), Das Ägyptische und die Sprachen Vorderasiens, Nordafrikas und der Ägäis (AOAT 310; Münster, 2004), 338-40 on the subject. 
Clear examples of this second type of ellipsis appear to occur only where the shared element is the subject of an active verb in both clauses. This suggests that ellipsis with a $s \underline{d} m=f$ is more restricted than ellipsis before $h r s \underline{d} m$ or stative.

Examples of subject ellipsis in passive clauses are also available. In this case, both verbs must appear in the passive, and while the pronominal suffix is lost from the second verb by the ellipsis process, the passive feature frequently remains visible as the passive morpheme $-w$. In the following, only examples with antecedents of female gender are cited in order to exclude the possibility that the verbs in the second clause could be stative forms:

(50) P. BM EA 10059, I3, I 5-I4, I = Grapow, Grundriss der Medizin V, 482:

jri.w tz.t jm=s, $r \underline{d} \underline{i} . w=\varnothing r \underline{h} n w j f=s$

A knot is to be made from it and inserted into her body.

(5 I) Urk. IV, I 800.5:

$n h m . t w j 3 w . t=f h f t-h r, d i \cdot . w=\varnothing n z n t j m$ hrrw=f

His office shall be taken away in public and be given to somebody who is his enemy.

(52) Helck, Die Prophezeiung des Nfr.tj, 40:

$n h m$ h.t $\approx r=f, r d \underline{d i} . w=\varnothing n n t j m r w t j$

Someone's goods will be taken away from him and given to an outsider.

(53) P. Berlin 3029, II I $_{5}=\mathrm{A}$. de Buck, 'The Building Inscription of the Berlin Leather Roll', Studia Aegyptiaca I (Roma, r 938), 51:

$w h q<w>3 w 3 . t, \underline{d i} . w=\varnothing m t 3$

The rope was released and put on the ground.

(54) H. M. Stewart, 'A Crossword Hymn to Mut', $\mathcal{F} E A 57$ ( I971), pl. 25, top line:

jw $n$ m3.tw mjt.t=f $\underline{d} r b 3 h, n s \underline{d} m=\varnothing \underline{d} r r k n \underline{t} r$

The like has not been seen before and not been heard since god's time.

\section{Ambiguous cases}

This paper has focussed on examples which are morphologically transparent. In practice, the vast majority of cases of this kind encountered in Egyptian texts displays ambiguous writings so that, for example, a decision between a stative and a subjectless $s \underline{d} m=f$ is not strictly possible, unless further criteria can be established in the future. I will finish with three typical debatable cases for illustration:

Urk. IV, 7.13-14:

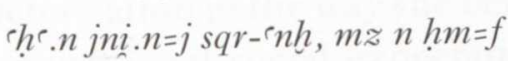

The intended meaning is clearly 'then I caught a captive and presented him to His Majesty'. Morphologically, the verb $m z$ could be either a stative or a subjectless $s \underline{d} m=f$. There is no object pronoun in the second clause. If $m z$ is interpreted as a stative, the lack of an object pronoun will be expected, whereas I have argued above that an object pronoun can be retained next to a subjectless $s \underline{d} m=f$. This may make a stative analysis probable here, but no certainty can be achieved at present. 
(56) Sinuhe R 7 = Koch, Die Erzählung des Sinuhe, 4:

shri $\mathrm{i}=f r$ p.t, $\underline{h} n m \mathrm{~m}$ jtn

He ascended to heaven and united with the sun.

As for $\underline{h} n m$, we face an ambiguity, presently unresolvable, between a stative and a subjectless $s \underline{d} m=f$.

(57) P. Ebers 86, 19-20 = Grapow, Grundriss der Medizin V, 68:

hr.tw wrh.tw=f $m$ mrh.t $r m . w 2 . n w$ hrw, wrh $m$ mrh.t $d b 3 . n w$ hrw

He then shall be anointed with fish fat on the second day, and be anointed with hippopotamus fat on the third day.

In this instance, the verb wrh can be interpreted as either a stative or a subjectless passive $s \underline{d} m .(w)=f$. 